\title{
Alle guten sind Drei!
}

Vom 26. bis 29. Oktober 2011 hat in Salzburg der 7. EFSMA European Sports Medizin Congress stattgefunden, wo nicht nur die wichtigsten Proponenten der Österreichischen Sportmedizin vor Ort waren, sondern auch internationale Experten/innen, die zum Großteil auch im Editorial oder Advisory Board der renommiertesten sportmedizinischen Journale zu finden sind. Ein Großteil von Ihnen findet sich ebenfalls im Advisory Board der Zeitschrift sport- und präventivmedizin.

Im Rahmen des Kongresses fand auch die Generalversammlung der ÖGSMP statt, wo unter anderem die Bedeutung der Zeitschrift sport- und präventivmedizin als offizielles Organ der Gesellschaft, auch beispielhaft für die mitteleuropäische Sport- und Präventivmedizin herausgestrichen wurde.

Bei der Generalversammlung der ÖGSMP wurde ein neuer Vorstand gewählt:

Präsident: Univ.-Prof. Dr. Karl Benedetto

Vizepräsidenten:

Prim. Dr. Angelika Karner-Nechvile, MSC, MBA

Univ.-Prof. Dr. Peter Schober

Eine Präsentation des neuen Vorstandes finden Sie im Blattinneren.

Seit dem Relaunch der Zeitschrift und der Kooperation mit Springer Wien sind mittlerweile 3 Jahre vergangen. Aufgrund von Veränderungen der Struktur des Springer Verlages wird ab dem Jahr 2012 die Zusammenarbeit der Zeitschrift sport- und präventivmedizin mit dem Springer Verlag nicht weitergeführt. Deshalb möchten wir uns, nach dem Motto „alle guten Dinge sind drei“ recht herzlich bei den verantwortlichen Damen und Herren bei Springer Wien bedanken, die uns eine wichtige Wegstrecke lang begleitet haben. Es waren sehr erfolgreiche 3 Jahre, die von einer sehr guten Atmosphäre und einer konstruktiven Zusammenarbeit geprägt waren.

Selbstverständlich wird die Zeitschrift sport- und präventivmedizin auch weiterhin als das wichtigste Medium dieser Fachrichtung erhalten bleiben. Konkrete Informationen über das Update der Zeitschrift finden Sie, werte Leserinnen und Leser, im Laufe des 1. Quartals 2012 auf die Homepage des Österreichischen Institutes für Sportmedizin (ÖISM): www.sportmedizin.or.at

In der aktuellen Ausgabe der sport- und präventivmedizin präsentieren wir Ihnen wieder interessanten Lesestoff, seien es Studien oder Fallberichte, die beliebten Doc's Tipps oder auch die Impressionen vom European Sports Medizin Congress 2011 in Salzburg.

Wir hoffen, dass Sie die Weiterentwicklung der Zeitschrift weiterhin als treue/r Leser/in begleiten und wünschen Ihnen frohe und besinnliche Weihnachtsfeiertage und ein wunderschönes, gesundes und erfolgreiches Jahr 2012.

Herzlichst

Univ.-Prof. Dr. Norbert Bachl

Herausgeber

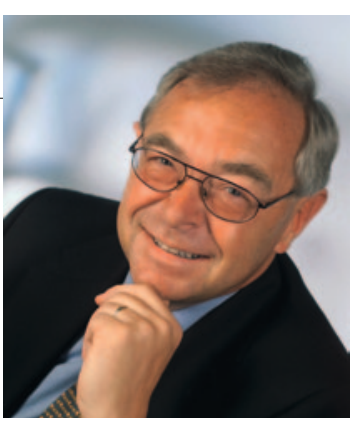

HERAUSGEBER

Univ.-Prof.

Dr. Norbert Bachl

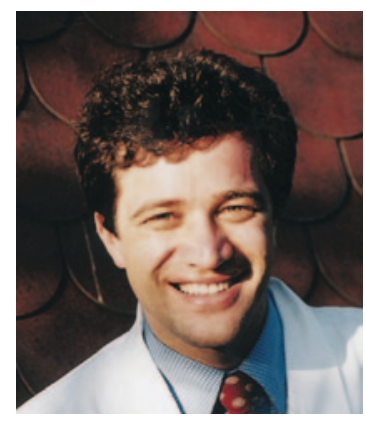

EDITOR IN CHIEF

Dr. Piero Lercher 